\title{
Improvement of Mathematical Support and Implementation of Modern Criteria of Juice Quality in the Automated Process Control Systems at the Sugar Mill Evaporation Station
}

\author{
Serhii Liashenko ${ }^{1}$, Alla Fesenko ${ }^{2}$, Oleksii Liashenko ${ }^{3}$, Victor Kis $^{4}$, Olena Turuta ${ }^{5}$ \\ ${ }^{1}$ Department of Life Safety and Law, Petro Vasylenko Kharkiv National Technical University of Agriculture, \\ Ukraine, lyashenkosa05@ukr.net \\ ${ }^{2}$ Department of Life Safety and Law, Petro Vasylenko Kharkiv National Technical University of Agriculture, \\ Ukraine, alla.ecology3006@gmail.com \\ ${ }^{3}$ Department of Computer Engineering and Control, Kharkov National University of Radio Electronics, Ukraine, \\ oleksii.liashenko@nure.ua \\ ${ }^{4}$ Department of Mechatronics and Mashine Elements, Petro Vasylenko Kharkiv National Technical University of \\ Agriculture, Ukraine, vkisprof@ukr.net \\ ${ }^{5}$ Department of Philosophy, Kharkiv National University of Radio Electronics, Ukraine,olena.turuta@nure.ua
}

\begin{abstract}
The article considers the operation of sugar mills in Ukraine and reasons affecting their efficiency. It determines the influence of the evaporation station operation on the energy efficiency of the factory and on qualitative indicators of the products. The study shows the influence of changes in juice qualitative indicators that form during the evaporation on sugar quality.

The directions in the work of the automated process control systems (APCS) are shown, which help to eliminate the problems that reduce the efficiency of the evaporation station. An important area in the APCS operation is the control of the product quality and energy efficiency regimes that ensure this quality. Due to the complexity of the juice evaporation in a multiple evaporation station and the influence of various indicators, both technological and qualitative, the main vectors of work in automated process control systems of the juice evaporation are determined.

An important way to improve the efficiency of the evaporator is the development and application of mathematical software at the APCS, which will reflect the real changes during the evaporation; and accordingly the software and equipment that are used for the control of the evaporation process and will appropriately respond to these changes.

The article considered the main criteria of sugar production efficiency, normative requirements, the oretical bases and practical experience of introduction and use of qualitative criteria in the APCS in the countries using energyefficient and competitive technologies of sugar production.

The study justifies the efficiency of the proposed product qualitative criteria in the method and algorithm to calculate the thermal evaporation regime for the mathematical support of the automated process control system. Accordingly, there is
\end{abstract}

reason to believe that the obtained qualitative criterion of efficiency, algorithm and method of calculation of the thermal process, which take into account both indicators of technological nature and indicators of the juice quality, can be used in mathematical software of the APCS at the sugar mill multiple evaporation station.

Key words: automated process control system (APCS), algorithm of thermal calculation, mathematical model, thermal calculation, multiple evaporation station (MES), criteria of efficiency, technological process.

\section{INTRODUCTION}

The application of modern technologies, equipment, information support systems in the automated process control system (APCS) of sugar production contributes to increase its efficiency. This issue is relevant due to the fact that sugar production is one of the most energy intensive and complex and this is becoming a key factor when energy resources are expensive. In addition, increasing the profitability of the industry requires the quality products. It is also important to determine the impact of various production factors on the technological process and their reflection and response in the system of mathematical support of automated process control. It can help to make the production more competitive and ensure appropriate product quality. To improve the efficience of the sugar mill technological complex operation it is advisable to supplement the automated systems with models, methods and algorithms for diagnosis and forecasting, which will allow real-time rapid detection, recognition and prediction of changes in the technological process $[1,2,3]$.

Indicators of sugar production efficiency are quality, energy efficiency and cost of the production. To improve the efficiency of these indicators it should be ensured by 
application of modern production technologies, equipment, and automated process control systems. At the same time, sugar production has strict requirements for product quality, energy consumption, process safety and clear operation of automated process control systems.

A sugar mill is described with the continuous energy and thermal processes. Both the energy efficiency of the entire sugar mill and the quality of the obtained products depend on the operation of the evaporator that distributes steam to other departments $[3,4,5]$.

The main equipment of the evaporator is a multiple evaporation station (MES) in which the thin juice evaporate to a given concentration and which provides secondary steam for heat exchange equipment in other departments of the factory.

The main task of the MES operation is to obtain concentrated thick juice at the evaporator output, from which it will be possible to obtain sugar of the appropriate categories. Non-compliance with the regimes of the MES operation and the inconsistency of the qualitative indicators in the obtained juice relative to the normative ones lead to additional energy consumption during the MES operation and other departments of the factory [4].

The use of effective APCS at the MES should provide: maintenance of the required technological regime with fixed values of technological indicators, stabilization of juice levels in the vessels, obtaining the required quality of the juice, safety of technological process and providing steam to other departments.

The basis of evaporation is the supply of the required amount of heat to a solution. While evaporating, the driving force of heat transfer is the temperature difference between the heating steam and the boiling point of the solution. Then interfacial exchange of matter occurs during evaporation. Such processes are mass transfer, which leads to the need to control the qualitative and technological indicators of evaporation $[3,4$, $5,6,7]$.

The major problems to determine the values of technological indicators for the APCS of the evaporator are:

- dynamics of fluctuations of the raw materials quality and parameters of heat-mass processes at the evaporation;

- unsatisfactory response of the control and measuring equipment of the APCS to technological changes in the evaporation;

- difficulty in determining the effective qualitative criterion to calculate the thermal process of evaporation in the mathematical support of the APCS $[8,9]$.

Improving the sugar quality as the major criterion of the production efficiency must be ensured by implementing the state regulations which will meet the quality requirements of sugar products used in the countries that are world leaders in sugar production $[1,10]$.
Thermal calculation of evaporation consists in determination of the heat transfer surface area of the evaporators and steam consumption. It is based on a rather complex method of calculating the thermal regime of the MES operation. This method uses a significant number of measured, calculated and tabular indicators, which, in turn, leads to a decrease in the efficiency of the evaporation and the APCS operation as well $[3,4,11]$.

Having analyzed the problems we can conclude that to increase the efficiency of evaporation we should improve mathematical support of the APCS, which is to apply a qualitative criterion in thermal calculation of the evaporation. Design and application of effective models for the APCS that respond to changes in technological process of the evaporation should increase production efficiency, energy efficiency and product quality.

The aim of the study is to increase the efficiency of the evaporator APCS at the sugar mill by improving mathematical support with using modern juice quality criteria. To achieve this aim we should solve the following tasks: analysis and justification to apply the effective juice quality criteria for the evaporation; development of the improved method and algorithm to calculate the thermal regime of the evaporation on qualitative indicators for mathematical support of the APCS at the evaporator.

\section{THE METHOD TO APPLY EFFECTIVE EVAPORATION CRITERIA FOR APCS}

\subsection{Analysis and justification of the modern effective criteria using for sugar mill evaporator automated process control system}

In order to harmonize the qualitative sugar indicators, the Ministry of Agrarian Policy of Ukraine has introduced the thesises of the EU Council Directive 2001/111 / EC from December, 20, 2001 on certain types of sugar intended for human consumption. The main qualitative indicators of sugar used by the leading countries producing sugar, as well as in accordance with DSTU 4623: 2006, are the content of sucrose, ash, reducing substances, moisture and color. The Order of the Ministry of Agrarian Policy dated November, 02, 2017 № 592 "On approval of the Requirements for types of sugars intended for human consumption" introduced the main quality indicators of sugar that meet international requirements $[1,10]$.

The use of mathematical software in the APCS to adjust the evaporation is mainly to solve problems of determining the effective quality functional. Based on the theory of optimal control, variants of construction of optimal speed systems and procedures of analytical design of optimal regulators were made out $[3,12,13,14]$.

Nowadays, in contrast to the classical control theory, which studies one-dimensional systems described with linear differential equations with constant coefficients, the modern control theory uses developments applied to different classes 
of multidimensional systems, and which can be described with different types of equations. The modern control theory includes the theory of optimal control. Optimal systems are systems in which the specified quality functionality is minimized or maximized during the operation. In addition, an important issue to determine the efficiency of the evaporation is the definition of control criteria $[15,16,17,18]$.

The multiple evaporation station works under uncertain conditions. These conditions, in turn, can be devided by the uncertainty of the purpose, and the uncertainty of the decision maker. These issues reduce the efficiency of the evaporation and whole sugar production at the factory. The application of the thermal process calculation in the mathematical software will effectively adjust the evaporation process. Uncertainty of the purpose is incorrect setting of the function criterion. In most cases, the minimum energy consumption is chosen as the management criterion at the MES. The rms-minimum deviation of the syrup concentration at the exit of the evaporator is chosen when the qualitative indicators are determined or the general criterion. But such setting the criterion leads to a lack of secondary steam for consumers, impractical excess of steam consumption, etc. The non-stationary operation of the MES caused by time-varying parameters of the boiled juice and variable heat and mass transfer evaporation indicators, makes more difficult the determination of this general criterion and reduces the efficiency of determining this criterion $[3,4]$.

Typical disturbances both external and internal leading to non-stationary operation of the APCS result in an increase in evaporation time, and, accordingly, to an increase of such a qualitative indicator as the colour.

To minimize the disturbances during the evaporation, it is needed to introduce a qualitative criterion in the thermal calculation of the evaporation and adjust the calculation method, as well as the algorithm to apply it.

\subsection{The improved method to calculate the thermal regime of the evaporation for APCS on the juice quality}

Improvment the method to calculate the thermal regime of the evaporator operation is to introduce a qualitative criterion for the juice in mathematical support of the APCS. To develop this technique, it is necessary to consider the physicochemical properties of the evaporating juice and the sequence of the juice passage in the MES. We should develop a procedure for using data in the calculation of the thermal evaporation process and the appropriate method and algorithm to calculate the thermal regime of the evaporator according to the qualitative indicator for APCS. The proposed approaches will allow to appropriately adjusting the evaporation.

We offer to use the standard order of the thermal calculation and take into account more effective qualitative indicators to implement effective management in the evaporation $[3,4]$.
The calculation of the multiple evaporation station is carried out in two stages. First the design calculation is made out to determine the parameters of the evaporator operation, the surface and dimensions of the heating chamber, and then the verification calculation has place to clarify the process parameters and heat transfer conditions.

The initial data for the MES calculation should include: the evaporator capacity and the number of vessels, the composition of the evaporated juice, its initial and final concentrations, the properties of the heating steam (pressure and temperature), and the secondary steam pressure.

The improved calculation of the thermal regime of the evaporator operation for APCS on qualitative indicators consists of the following subroutines:

1. The water evaporation calculation

1.1 It is considered the evaporation of water from thin juice (solution) in the evaporator, which is described as the equation of material balance $[3,4]$

$$
\mathrm{G}_{\mathrm{i}}=\mathrm{G}_{\mathrm{f}}+\mathrm{W},
$$

where $G_{i}$ - capacity on an initial solution, $\mathrm{kg} / \mathrm{h} ; \mathrm{G}_{\mathrm{f}}$ - capacity on a final solution, $\mathrm{kg} / \mathrm{h} ; \mathrm{W}$ - total amount of the evaporated water, $\mathrm{kg} / \mathrm{h}$.

Equality of firm weight should remain in the solution that evaporates in the MES. It is determined with such correlating indicators as sugar concentration in the solution, colour, turbidity, etc. According to the method of thermal calculation of the evaporation, the equation (1) can be shown as follows

$$
\mathrm{G}_{\mathrm{i}} \mathrm{c}_{\mathrm{i}}^{\mathrm{k}}=\mathrm{G}_{\mathrm{f}} \mathrm{c}_{\mathrm{f}}^{\mathrm{k}},
$$

where $c_{i}^{k}$ and $c_{f}^{k}-$ the color-adjusted initial and final concentration of the evaporating solution, $\%$.

Used the formulas (1) and (2), we can determine the adjusted total amount of water (W) that evaporates and is necessary to obtain a quality product

$$
\mathrm{W}=\mathrm{G}_{\mathrm{i}}\left(1-\mathrm{c}_{\mathrm{i}}^{\mathrm{k}} / \mathrm{c}_{\mathrm{f}}^{\mathrm{k}}\right) .
$$

To determine the influence of the colour $(\mathrm{K})$ as a qualitative indicator of sugar on the evaporation process we need to consider the physical essence of the relationship between the colour and concentration of the solution. The correlation between the concentration and the color in the solution, according to the approved method given in DSTU 4866: 2007 / GOST 12572-2007 is determined from the formula [10]

$$
\mathrm{K}=1000 \cdot \mathrm{D}_{420} / \mathrm{c} \cdot 1 \text {, ICUMSA units }
$$

where $\mathrm{c}-$ a measured concentration, $\%$; $\mathrm{D}_{420}$ - the optical density of the sugar solution at a wavelength of $420 \mathrm{~nm} ; 1$ length of the cuvette, $\mathrm{cm}$ ( $5 \mathrm{~cm}$ for thick juice); 1000 - colour conversion factor into ICUMSA units. 
Accordingly $\mathrm{c}$ is determined from the following expression $[4,10]$

$$
\mathrm{c}=\mathrm{DM} \cdot \rho / 100,
$$

where DM - the mass fraction of dry matter in juice, $\%$; $\rho-$ the density of the sugar solution, gr/ $\mathrm{sm}^{3} ; 100$ - a coefficient to transferpercents into grams.

Then the formula to determine the normative colour can be shown as follows

$$
K_{n}=100 \cdot 1000 \cdot D_{420} / D M \cdot \rho \cdot 1 .
$$

To determine the influence of the colour found from the expression (6) we need to substitute the obtained colourvalues in formula (4), and then the concentration adjusted on the normative colour, with values of the density and the dry matter for the corresponding stages of the evaporation will be

$$
\mathrm{c}^{\mathrm{k}}=100 \cdot 1000 \cdot \mathrm{D}_{420} / \mathrm{K}_{\mathrm{n}} \cdot 1 .
$$

While determining the amount of evaporating water W (3) and in further calculations of the method and the thermal regime algorithm for the evaporator operation we should use the value of the obtained adjusted concentration (7).

1.2 Accordingly, we can determine from the formula (3) the approximate amount of water that will evaporate.

1.3 The final concentration of the solution at the stages adjusted for the qualitative indicator by the formula (3), can be determined from the following expression

$$
\mathrm{c}_{\mathrm{f} 1-5}^{\mathrm{k}}=\mathrm{G}_{\mathrm{i}} \cdot \mathrm{c}_{\mathrm{i}}^{\mathrm{k}} / \mathrm{G}_{\mathrm{i}}-\mathrm{W}_{1-5} .
$$

2. Determination of temperature depressions and the solution density in stages

2.1 According to the final values of concentrations $\mathrm{c}_{\mathrm{f} 1-5}$ we determine the normal temperature depression in the stages, $\Delta_{0},{ }^{\circ} \mathrm{C}$ and calculate the total temperature depression.

2.2. We determine the steam temperature loss between the evaporators $\sum \Delta_{1}^{1-5}$.

2.3 We find the total useful difference temperatures of the facility $\sum \Delta \mathrm{t}$.

2.4 We calculate the temperature of heating steam in the stages, $\mathrm{T},{ }^{\circ} \mathrm{C}$; the boiling temperature of the solution, $\mathrm{t}_{\mathrm{k}},{ }^{\circ} \mathrm{C}$; the temperature of secondary steam, $\mathrm{t}_{\mathrm{ss}}{ }^{\circ} \mathrm{C}$; the final concentration of the solution in the stages, $\mathrm{x}_{1-5}, \%$; the solution density in the stages, $\rho_{\mathrm{s} 1-5}, \mathrm{~kg} / \mathrm{m}^{3}$.

3. Adjustment of the temperature depression and the solution pressure

3.1 The real temperature depression in the stages, $\Delta,{ }^{\circ} \mathrm{C}$

$$
\Delta_{1-5}=0.0162\left(\mathrm{~T}^{2} / \mathrm{r}_{\mathrm{w}}\right) \Delta_{0},{ }^{\circ} \mathrm{C},
$$

where $\mathrm{T}$ - temperature of secondary steam, $\mathrm{K} ; \mathrm{r}_{\mathrm{w}}$ - heat and evaporation energy, $\mathrm{kJ} / \mathrm{kg}$.

\subsection{The total temperature depression $\sum \Delta$.}

3.3 The optimal height of filling the tubes with the solution using the empirical formula

$$
\mathrm{H}_{01-5}=\left[0.26+0.0014\left(\rho_{\mathrm{s}}-\rho_{\mathrm{w}}\right)\right] \mathrm{l}_{\mathrm{tb}},
$$

where $\mathrm{l}_{\mathrm{tb}}-$ length of the heating tubes, $\mathrm{m}$.

3.4 The hydrostatic pressure of the column in the middle of the heating tubes

$$
\Delta \mathrm{P}_{1-5}=\mathrm{g} \cdot \mathrm{H}_{01-5} \cdot \rho_{\mathrm{s} 1-5} / 2, \mathrm{~Pa} .
$$

3.5 The solution pressure in the evaporator stages in the middle of the heating tubes

$$
\mathrm{P}_{\mathrm{m}}^{1-5}=\mathrm{P}_{\mathrm{sS}}^{1-5}+\Delta \mathrm{P}_{1-5}, \mathrm{~Pa} .
$$

4. Determination of the true temperatures of heating steam, secondary steam, and solution

To find out the actual values of the temperatures of heating steam, secondary steam, boiling the solution, the useful temperature difference in evaporators, we should calculate the temperature losses due to the hydrostatic pressure.

4.1 We calculate the value of temperature losses due to the hydrostatic effect

$$
\Delta_{\mathrm{h}}^{1-5}=\mathrm{t}_{\mathrm{m}}^{1-5}-\mathrm{t}_{\mathrm{ss}}^{1-5}
$$

and the total losses $\sum \Delta$.

4.2 We find the total useful temperature difference for the evaporator $\sum \Delta \mathrm{t}$.

4.3 The distribution of the useful temperature difference in the evaporators is found from the expression

$$
\Delta \mathrm{t}_{1-5}=\sum \Delta \mathrm{t} \cdot \sqrt{\mathrm{Q}_{\mathrm{tb}} / \mathrm{K}_{\mathrm{tb}}} / \sqrt{\sum \mathrm{Q}_{\mathrm{tb}} / \mathrm{K}_{\mathrm{tb}}} .
$$

5. Calculation of the heating steam consumption, evaporated water in the evaporators, the final concentrations

In this subroutine we determine the consumption of heating steam, the consumption of evaporated water in the evaporators, the final concentrations of the solution (thick juice) and the approximate thermal loads on the evaporators.

5.1 The heating steam consumption is determined from the equation of heat balance, which can be in the form

$$
\begin{aligned}
& \mathrm{D}_{1-5}=\mathrm{A} \cdot \mathrm{W}_{1-5}\left(\mathrm{H}_{\mathrm{ss}}^{1-5}-\mathrm{c}_{\mathrm{i} 1-5} \mathrm{t}_{\mathrm{i} 1-5}\right) /\left(\mathrm{H}_{\mathrm{hs} 1-5}-\mathrm{H}_{\mathrm{c} 1-5}\right)+ \\
& \quad+\mathrm{A}\left(\mathrm{G}_{\mathrm{i}}-\mathrm{W}_{1-5}\right) / \mathrm{H}_{\mathrm{hs} 1-5}-\mathrm{H}_{\mathrm{c} 1-5} \times \\
& \quad \times\left(\mathrm{c}_{\mathrm{s} 1-5} \mathrm{t}_{\mathrm{f} 1-5}^{\prime}-\mathrm{c}_{\mathrm{i} 1-5} \mathrm{t}_{\mathrm{i} 1-5}^{\prime}+0,01 \mathrm{x}_{\mathrm{f} 1-5} \Delta \mathrm{q}_{1}\right) \div \\
& \div\left(\mathrm{H}_{\mathrm{hs} 1-5}-\mathrm{H}_{\mathrm{c} 1-5}\right), \mathrm{kg} / \mathrm{h}
\end{aligned}
$$


where $\mathrm{A}=1.03$ - heat loss that equals to $3 \%$ of the heating steam;

$\mathrm{H}_{\mathrm{sS}}^{1-5}$ - enthalpy of the secondary steam (tabular values), $\mathrm{kJ} /\left(\mathrm{kg}^{\circ} \mathrm{C}\right)$;

$\mathrm{c}_{\mathrm{i} 1-5}$ - the initial concentration, \%;

$\mathrm{H}_{\mathrm{hs} 1-5}$ - enthalpy of the heating steam, $\mathrm{kJ} /\left(\mathrm{kg}^{\circ} \mathrm{C}\right)$;

$\mathrm{H}_{\mathrm{c} 1-5}$ - enthalpy of the condensate, $\mathrm{kJ} /\left(\mathrm{kg}^{\circ} \mathrm{C}\right)$.

5.2 The heat load of the evaporators is determined from the expression

$$
\mathrm{Q}_{1-5}=\mathrm{D}_{1-5}\left(\mathrm{H}_{\mathrm{hs} 1-5}-\mathrm{H}_{\mathrm{c} 1-5}\right), \mathrm{kW}
$$

6. Determination of the heat convection and heat transfer coefficients

In this subroutine we calculate the heat transfer coefficients, heat loads and heat convection coefficients with using tabular data.

6.1 The heat transfer coefficient is determined

$$
\mathrm{K}_{1-5}=1 / \frac{1}{\alpha_{1}^{1-5}}+\sum \delta^{1-5} / \lambda^{1-5}+1 / \alpha_{2}^{1-5},
$$

where $\alpha_{1}^{1-5}$ - the heat transfer coefficient from steam to the outer wall of the tube; $\sum \frac{\delta}{\lambda}-$ the total thermal resistance of the tube wall and scale; $\alpha_{2}^{1-5}$ - the heat transfer coefficient from the inner wall of the tube to the boiling solution (juice).

7. Calculation of the heat load and the heating areas of the evaporator

In this subroutine we find the distribution of the useful temperature difference in the evaporators of the MES, the heat transfer surface of the evaporator and the number of heating tubes.

7.1 The distribution of the useful temperature difference in the evaporators is determined according to the formula

$$
\mathrm{t}_{1-5}^{\mathrm{u}}=\sum \Delta \mathrm{t} \cdot \sqrt{\mathrm{Q}_{1-5} / \mathrm{K}_{1-5}} / \sqrt{\sum \mathrm{Q}_{\mathrm{t}} / \mathrm{K}_{\mathrm{t}}},{ }^{\circ} \mathrm{C}
$$

7.2 The heat transfer surface of the evaporator

$$
\mathrm{F}_{1-5}=\mathrm{Q}_{1-5} / \mathrm{K}_{1-5} \cdot \mathrm{t}_{1-5}^{\mathrm{k}} \text {. }
$$

7.3 The number of the heating tubes

$$
\mathrm{n}_{1-5}=\mathrm{F}_{1-5} / \pi \cdot \mathrm{d}_{\mathrm{in}} \cdot \mathrm{l}_{\mathrm{tb}}
$$

\section{RESULTS AND DISCUSSION}

\subsection{Algorithm to apply the thermal regime calculation of the evaporation for mathematical support of APCS}

Algorithm to apply the thermal regime calculation of the evaporation is based on the following functions:
1. Informational functions: collection, processing and storage of information about the initial and final state of the control object, as well as indicators that describe the state of the object during the evaporation.

2. Determination of technological and technical parameters deviations from the calculated normative values, as well as the state of equipment and the evaporating juice.

3. Determination of values by means of the calculation method.

4. Display and registration of information.

5. Exchange of information for APCS between the other production departments of the sugar mill and the operator.

The control functions should maintain the extreme values of the control criterion in the event disturbances affecting the evaporation process. The control functions are divided into the following groups:

- the first - determining the optimal impact;

- the second - implementation of this influence through the formation of control influences on the management object (stabilization, program management, program-logical management).

The scheme of the order to apply data in the calculation of the thermal evaporation process for mathematical support of the APCS at the MES is shown in Figure 1 [19].

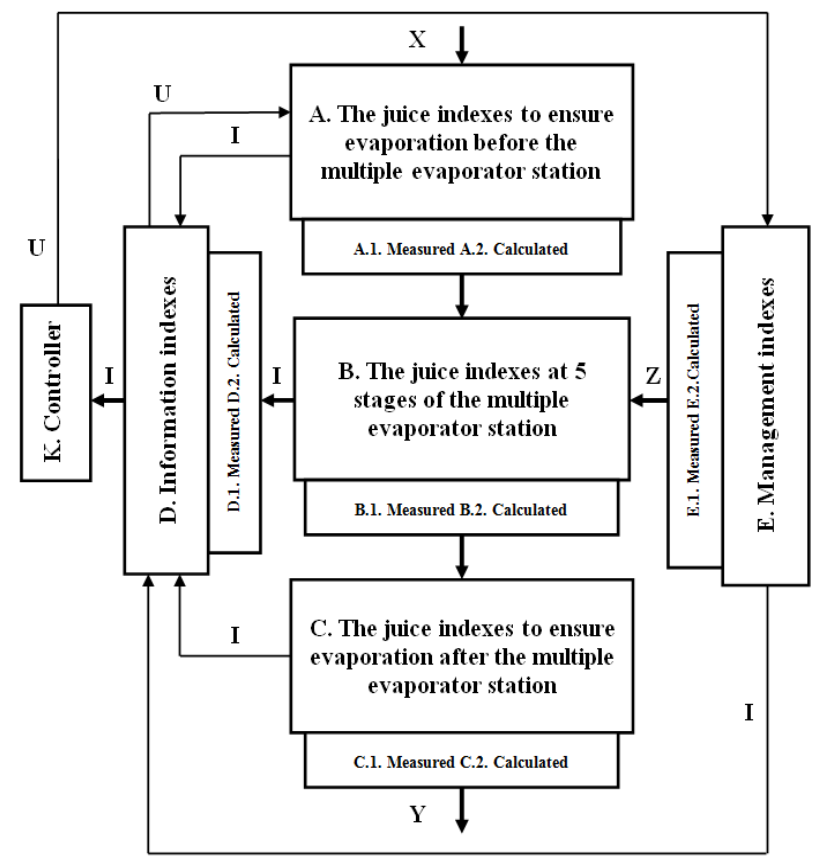

Figure 1: The scheme of the order to apply data in the calculation of the thermal evaporation process for mathematical support of the APCS at the MES: $\mathrm{X}$ is the input vector; $\mathrm{Y}$ is the output vector; $\mathrm{U}$ is the control vector; $\mathrm{Z}$ is the vector of disturbances; I is the information vector; $\mathrm{A}$ is the information indicators for APCS before the evaporator; $\mathrm{B}$ is the information indicators from the object to management by APCS; $\mathrm{C}$ is information indicators for APCS after the evaporator; $\mathrm{D}$ is processing of the information indicators; $\mathrm{E}$ is information values of management indicators; $\mathrm{K}$ is a controller 
All information indicators I (measured, referential and calculated), from the control object in Fig. 1 (A, B, C, E) provide information on a PC (D) toprocessdata and calculate the thermal regime of the MES operation at the appropriate time. The thermal calculation results are directed to the controller (K) from the PC (D).

The introduction of indicators on the PC (D) with the relevant data and results of laboratory tests and calculations, as well as the characteristics of the thermal regimes of the MES operation helps to take into account changes in the evaporator operation and change the thermal calculation of operating regimes using the colour criterion. The data obtained from the database (D) corrected by the qualitative criteria, through the controller $(\mathrm{K})$ is fed to the database A for verification, and to the database (E) for management of the control object. The management is carried out due to changes in the thermal load of the evaporators for the adjusted calculation.

To ensure effective control of the evaporation process at the MES (the control object B), in accordance with the scheme of data application shown in Fig. 1, it is proposed to apply the calculation of the evaporation, which consists of subroutines with measured, referential and calculated information indicators in the data application algorithm.

The algorithm to apply calculation of a thermal regime of evaporation, which uses qualitative indicators, for mathematical support of APCS at the evaporator should include the following order of actions:

1. Before entering the thin juice from the defecosaturation department to the evaporator we should determine compliance with the normative indicators of input juice technological indicators for 4 categories that describe the quality of sugar and are used in the improved method of the thermal regime calculation (2.2). The use of these indicators, which meet the regulatory technological and qualitative requirements, can also ensure the discharge of the thick juice from the MES with the appropriate qualitative indicator (the color).

Indicators characterizing the thin juice that should come to the evaporator are entered the database (D) of the APCS of the evaporator to calculate the thermal regime of the MES operation. After calculating the required thermal regime of the MES, the obtained data are submitted to the database A and E.

1.1 If the values of the information indicators obtained from the database (A) to the database (D) meet the normative ones (for 4 groups of sugar quality), it is necessary to calculate the thermal regime of the evaporator operation; and taking into account the obtained technological and qualitative indicators, through the controller (K) we can affect the thermal regime of the evaporators operation with the executive bodies of control (E).

1.2. If the indicators obtained from the database (A) and provided to the database (D) for analysis do not meet the regulations, it is necessary to provide the information indicators to the database (A) to take action to eliminate these differences. Then we need to recalculate the operation regime, or carry out additional technological measures to improve technological and qualitative indicators of thin juice in the juice purification department.

2. After the evaporation process has started, according to the thermal calculation, in the course of the process, the information indicators of the evaporation process are obtained from the database (B) of the evaporator and are used to adjust calculation of the thermal regime. The calculation is adjusted for different thermal regimes of the evaporator operation, which are described with the values of qualitative indicators for 4 groups. The adjustment must be made by recalculating the thermal regime of the evaporator operation, or by the introduction of an appropriate factor that can adjust the quality model (6) for the controller $(\mathrm{K})$ in accordance with the quality groups.

2.1 If the values of qualitative and technological indicators of the evaporation process obtained from all evaporators of the MES (B) and sent to the database (D), after checking for compliance with the values of qualitative indicators for 4 groups of the product quality, meet the normative values, the process continues and recalculation of the thermal regime of operation and adjustment is not carried out.

2.2 If there is discrepancy of the qualitative and technological indicators obtained from the database (B) and sent to the database (D), the regimes of the evaporator operation are recalculated according to the above procedure, and the adjusted values are fed to the controller $(\mathrm{K})$. The corrected values from the controller are fed to the control (E).

3. At the exit of the thick juice from the evaporator, the values of technological and qualitative indicators from the database (C) are sent to the database (D), where the values of these indicators are checked.

3.1 If the final indicators of the thick juice from the MES, after checking for compliance in the database (D), meet the normative calculated values, the evaporation process will continue.

3.2 If thick juice quality does not meet the normative calculated values, the obtained indicators are submitted to the database (D), where the calculation of the evaporation should be adjusted, and after recalculation the data are submitted to the controller (K) to further adjust operation of the control body (E).

The block diagram of the algorithm to apply calculation of the thermal regime of evaporationfor mathematical support of APCS at the evaporator is given in Figure 2. 


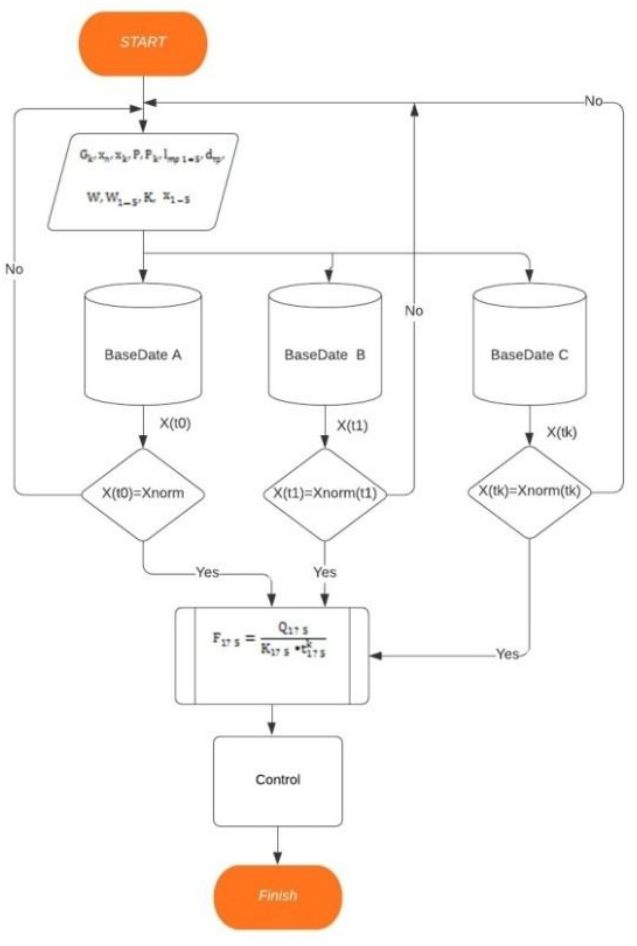

Figure 2: The block diagram of the algorithm to apply calculation of the thermal regime of evaporation for mathematical support of APCS at the evaporator

\subsection{Determination of the thermal calculation indicators in the subroutine 1 on qualitative indicators}

To estimate the thermal calculation indicators we used the data obtained from the sugar mills with quality regimes of the evaporator operation. For comparison, the calculations of thermal regime of the evaporation are given, which have been made out according to the standard method and the improved one [19].

The thermal calculation based on the qualitative indicators in the subroutine 1 to determine the adjusted concentration (7) according to the proposed method will be as follows

- If the colour of the thin juice at the entrance to the evaporator equals $\mathrm{K}=220$ ICUMSA units to produce sugar of the 1th group

$$
\begin{aligned}
& \mathrm{c}^{\mathrm{k}}=100 \cdot 1000 \cdot \mathrm{D}_{420} / \mathrm{K}_{\mathrm{n}} \cdot 1= \\
= & 100 \cdot 1000 \cdot 0.18 / 220 \cdot 5=15.6 \%,
\end{aligned}
$$

where $\mathrm{D}_{420}$ - the optical density of the sugar solution (0.18) if $\mathrm{DM}$ (dry matter) is equal $15.8 \%$; and $\rho=1.063 \mathrm{gr} / \mathrm{sm}^{3}$.

100 - a percentage conversion factor into grams.

- If the thick juice colour at the exit from the evaporator equals $K=250$ ICUMSA units to produce sugar of the 1th group

$$
\begin{gathered}
c^{\mathrm{k}}=100 \cdot 1000 \cdot \mathrm{D}_{420} / \mathrm{K}_{\mathrm{n}} \cdot 1= \\
=100 \cdot 1000 \cdot \mathrm{D}_{422} / \mathrm{K}_{\mathrm{H}} \cdot 1= \\
=100 \cdot 1000 \cdot 0.95 / 250 \cdot 5=75 \%,
\end{gathered}
$$

where $\mathrm{D}_{420}=0.95, \mathrm{DM}=66 \%, \rho=1.322 \mathrm{~g} / \mathrm{sm}^{3}$.

The results obtained, help to conclude that the concentration values that are required to determine the evaporated water amount in the subroutine 1 are indeed adjusted for the colour. This is confirmed by the model describing the influence of the thermal regime of the evaporator on the colour. The juice colour change sensitivity to changes in thermal processes during evaporation is equal $1.0-1.5 \%[4,11,19]$.

\section{CONCLUSION}

The work considered the issue of increasing efficiency of sugar mill evaporator APCS by applying the improved mathematical support with the use of modern quality criteria. We carried out analysis and substantiation of the effective juice quality criteria application for APCS at the evaporator, which meet modern requirements. The application of the improved method of a thermal regimecal culation for the evaporation of thin juice on qualitative indicators of juice is theoretically substantiated. According to the data application scheme, the algorithm to control thermal regimes of operation has been developed for the automated process control system of the MES with using the improved calculation procedure for mathematical software.

The values of quality indicators used in the proposed method, when calculating the thermal regime of the MES, really depend on changes in the material and thermal balance of the evaporating juice. The juice concentration adjusted for qualitative indicators according to the thermal regime operation calculation is confirmed by quite high indicators of the sensitivity of the change in the juice colour to changes in the thermal process. The proposed method and the algorithm help to increase the quality of sugar products and the competitiveness of sugar production. [19].

\section{REFERENCES}

1. The requirements for sugar production meet the European standards. Government portal. URL: https://www.kmu.gov.ua/ua/news/vimogi-do-virobnictvacukru-privedeno-u-vidpovidnist-do-yevropejskih

2. Lajos Rozsa, A few thoughts on automation in sugar manufacturing, International Sugar Journal, vol 106, no. 1252, pp. 156-166, April 2003.

3. Maria P. Marcos, Jose L. Pitarch, Christian Jasch, Cesarde Prada. Optimal distributed load allocation and resource utilisation in evaporation plants, Computer Aided Chemical Engineering, vol. 46, pp. 979-984, 2019. https://doi.org/10.1016/B978-0-12-818634-3.50164-8

4. K. Shtangeyev. Evaporators and heat schemes of sugar mills. Kyiv, 2015, pp. 23-32.

5. Somchart Chantasiriwan. Increased Energy Efficiency of a Backward-Feed Multiple-Effect Evaporator Compared with a Forward-Feed Multiple-Effect 
Evaporator in the Cogeneration System of a Sugar Factory, Processes, vol. 8 no. 3, p. 342, March 2020. https://doi.org/10.3390/pr8030342

6. Christopher P. East, Christopher M. Fellows, William O. S. Doherty.Chapter 25 - Scale in Sugar Juice Evaporators: Types, Cases, and Prevention, Mineral Scales and Deposits. Scientific and Technological Approaches, pp. 619-637, 2015.

7. Reva L., Vygovskyi V. Improvement of the quality and yield of sugar by using of adsorption purification of syrup in the modern technological scheme, in Proc. International Scientific-Technical Conf. Prospectives of Ukrainian sugar production development, Kyiv, pp. 89-96, 2019.

8. Alejandro Merino, Luis Felipe Acebes, Raúl Alves, César de Prada. Real Time Optimization for steam management in an evaporation section, Control Engineering Practice, Volume 79, Pages 91-104, October 2018.

https://doi.org/10.1016/j.conengprac.2018.07.010

9. A. V. Ensinas, S. A. Nebra, M. A. Lozano, L.Serra. Design of Evaporation Systems and Heaters Networks in Sugar Cane Factories Using a Thermoeconomic Optimization Procedure, Int. J. of Thermodynamics, vol. 10, no. 3, pp. 97-105, March 2007.

10. DSTU 4623-2006. National standards of Ukraine. White sugar. Technical conditions, published in Kyiv, 2007, pp. 1-12.

11. V. Didur, M. Struchayev. Heat engineering, heat supply and heat utilization in agriculture. Kyiv, 2008, pp. 34-37.

12. S. Lyashenko, O. Lyashenko. Automation of suga rproduction technological processes on the basis of the smart approach. Motrol. Commission of motorization and energetics in agriculture. Vol. 15, №7. pp. 145-150. 2013.

13. A. Kovalenko, A. Shamraev, E. Shamraeva, A. Dovbnya, O. Ilyunin. Green Microcontrollers in Control Systems for Magnetic Elements of Linear Electron Accelerators. Green IT Engineering: Concepts, Models, Complex Systems Architectures. Studies in Systems, Decision and Control series. Springer International Publishing Switzerland, pp. 283-305, 2017. https://doi.org/10.1007/978-3-319-44162-7_15

14. A. Satif, L. Hlou, H. Dahou, M. Mekhfioui, R. Elgouri. Grid-connected photovoltaic systems synchronization algorithms under disturbances: a low-cost hardware implementation using Arduino DUE, International Journal of Emerging Trends in Engineering Research, vol. 8, no. 3, pp. 674-682, March 2020. https://doi.org/10.30534/ijeter/2020/11832020

15. A. Ladanyuk, V. Kyshenko, O. Shkolna. Evaporator control under conditions of uncertainty: intellectualization of applied functions. Scientific works of The National University of Food Technologies, volume 21, issue 6, pp.7-15, 2015.

16. O. Liashenko, O. Barkovska, Ch. Al-Atroshi, O. Datsok, S. Liashenko. Model of the Work of the Neurocontroller to Control Fuzzy Data from the Sensors of the Climate Control Subsystem "Smart
House", International Journal of Advanced Trends in Computer Science and Engineering,vol. 8, no. 1.2, pp. 70-74, 2019.

17. Aaron Don M. Africa, Patrick Bernard T. Arevalo, Arsenic S. Publico, Mharela Angela A. Tan. A Fuzzy Neural Control System, International Journal of Emerging Trends in Engineering Research, vol. 7, no. 9, pp. 323-327, September 2019. https://doi.org/10.30534/ijeter/2019/15792019

18. Christopher D. Rhoten. Influence of sugar and syrup pH value on overall color rise in the sugar end and color of final molasses, Sugar Industry, pp. 527 - 532, 2011.

19. S. Liashenko, A. Fesenko, O. Liashenko, V. Kis, H. Ivashchenko. Determination and Estimation of the Influence of Different Types of Disturbances on the Thick Juice Colourto Apply in Automated Process Control Systems of the Sugar Mill Evaporator, International Journal of Emerging Trends in Engineering Research, Volume 8(5), pp. 2133 - 2139, May 2020. https://doi.org/10.30534/ijeter/2020/107852020 